\title{
Inflow of Air Required at Wall and Ceiling Apertures to Prevent Escape of Fire Smoke
}

\author{
GUNNAR HESKESTAD and ROBERT D. SPAULDING \\ Factory Mutual Research Corporation \\ 1151 Boston-Providence Turnpike \\ Norwood, Massachusetts 02062, USA
}

\section{ABSTRACT}

Experiments have been conducted to determine critical Froude numbers associated with required inflow of air to a fire space through wall and ceiling apertures to prevent escape of smoke. The experiments were conducted mostly on reduced, model scale, with verification in a $2.4 \mathrm{~m}$ high test room. Critical Eroude numbers, as formulated, were insensitive to aperture geometry. Those for wall apertures varied slowly and predictably with the vertical temperature distribution in the room, consistent with a discharge coefficient of 0.64 for the inflow. Those for ceiling apertures exhibited a dependence on an aperture Grashof number, with both a highGrashof number asymptote and an apparent low-Grashof number asymptote. While discharge coefficients for wall apertures can be considered constant near 0.64 for aperture Froude numbers larger than critical, the discharge coefficient for celling apertures increased from 0.19 near the critical Froude number, toward the familiar isothermal value for sharp-edged orifices of 0.61 near a Froude number seven times larger than the critical.

KEYWORDS: Compartment Fire, Smoke Control, Apertures, Discharge Coefficient

\section{NOMENCLATURE}

A area of aperture

C discharge coefficient

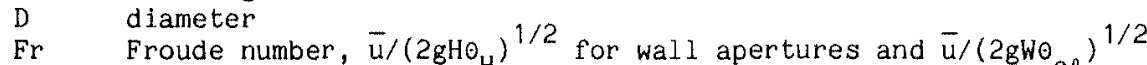

Fr Froude number, $\overline{\mathrm{u}} /\left(2 \mathrm{gH} \Theta_{\mathrm{H}}\right)^{1 / 2}$ for wall apertures and $\overline{\mathrm{u}} /\left(2 \mathrm{gW} \Theta_{\mathrm{cl}}\right)^{1 / 2}$
for ceiling apertures

$\mathrm{Fr}_{\mathrm{c}}$ critical value of $\mathrm{Fr}$ to prevent escape of smoke from aperture

$\mathrm{Gr}$ Grashof number, Eq. (7) for wall apertures and Eq. (9) for ceiling apertures

8 acceleration of gravity

$\mathrm{H}$ height of aperture or passage

L axial length of opening

in mass flow rate 


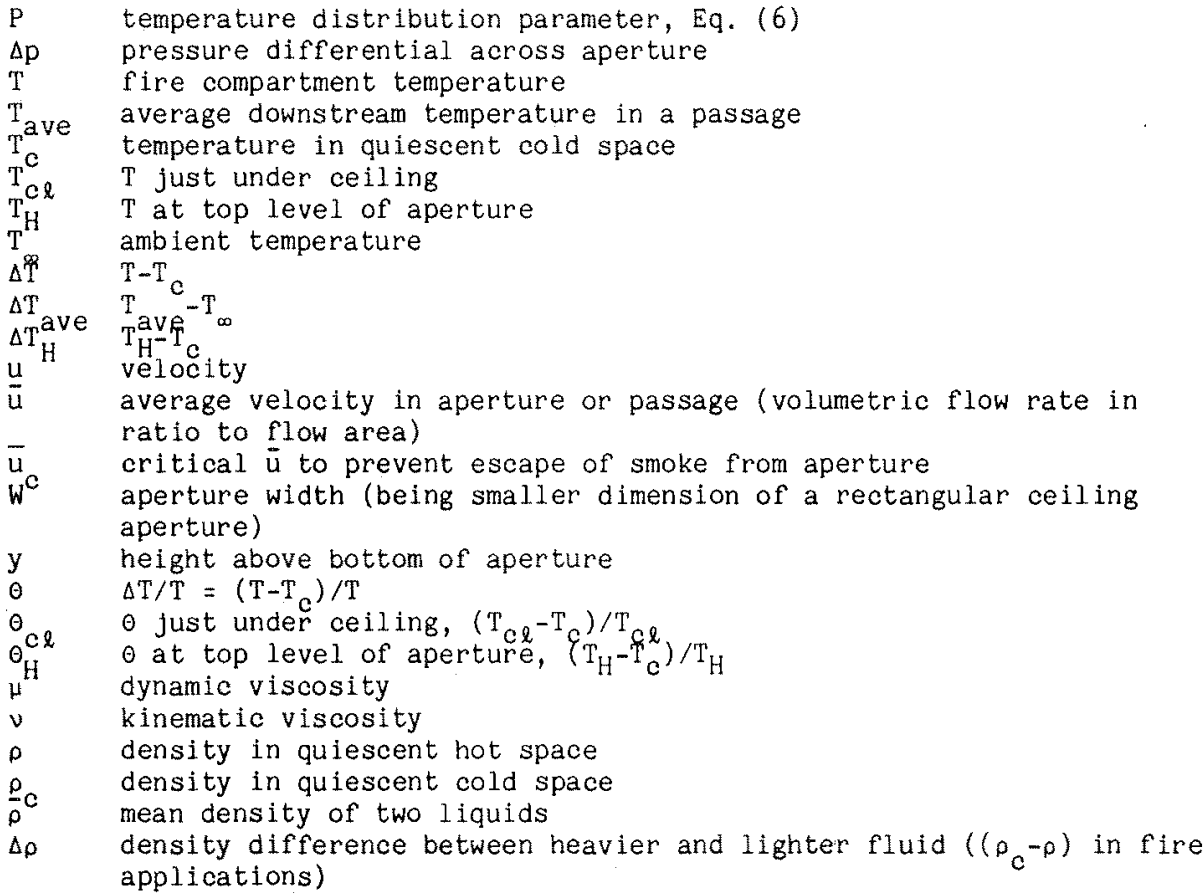

\section{INTKODUCTION}

Smoke control may be practiced according to two different objectives. One objective might be to limit smoke to a fire zone, which always includes the compartment on fire, but may also include contiguous space on the same floor, even an entire floor or several floors of a building. The other objective might be to limit smoke to a fraction of the space of the fire compartment. Accordingly, one may speak of "zoned smoke control" and "compartment smoke control." The present investigation was undertaken to provide data for the design of zoned smoke control systems, addressing specifically the minimum flow rates needed at openings in a boundary to a fire zone from the surrounding space to prevent escape of smoke, i.e., contamination of the surrounding space.

Directly related previous work includes the investigation by Thomas [1] on the minimum air velocity necessary to prevent smoke flowing upstream in a horizontal passage, derived from experiments burning methyl alcohol in a trough across the floor of a wind turnel. The oritical average velocity in the passage, $\bar{u}$, can be expressed in terms of a critical Eroude number (assuming 80 percent of the heat generated by the fire source was transferred to the air in the experiments):

$\overline{\mathrm{u}}_{\mathrm{c}} /[2 \mathrm{gH \Delta \textrm {T }} \text { ave } / \mathrm{T} \text { ave }]^{1 / 2}=0.79$.

Epstein [2], and Epstein and Kenton [3], have studied the combined natural and forced flows through openings in horizontal partitions using a heavier liquid, brine, on top of the partition and a lighter liquid, fresh water, below the partition. The later study [3] concentrated on critica] 
Froude numbers for transition between unidirectional and bidirectional flows in circular openings (for the most part) of various length-to-diameter ratios, $L / D$. The critical Froude numbers were approximately constant for $L / D$ in the range 0.01 to 0.06 , then approximately doubled in value as $L / D$ increased to 0.6 , eventually decreasing to about one half their $10 \mathrm{H}-\mathrm{L} / \mathrm{D}$ value for further increases in $\mathrm{L} / \mathrm{D}$ up to 10 . In terms of an analogue critical Froude number applicable to escape of smoke (transition to bidirectional flow) from an opening in the roof of a fire compartment,

$\mathrm{Fr}_{\mathrm{c}}=\tilde{u}_{\mathrm{c}} /[2 \mathrm{gD} \Delta \mathrm{T} / \mathrm{T}]^{1 / 2}$,

the low-L/D values measured by Epstein and Kenton [3] correspond to an average value, $F r_{c}=0.18$ (range from 0.16 to 0.20 ). The Grashof number of the experiments,

$\mathrm{Gr}=(\Delta \rho / \bar{\rho}) \mathrm{gD} \mathrm{D}^{3} / \nu^{2}$

has been calculated to have ranged from $2.0 \cdot 10^{7}$ to $1.4 \cdot 10^{8}$.

Other related work includes the investigation of Shaw [4] on combined natural and forced convection through openings in a vertical partition, as well as the measurements by Steckler et al. [5] of flow coefficients for fire induced flow through wall openings.

Details of the investigation presented here can be found elsewhere [6].

\section{THEORETICAL CONCEPTS}

\section{Wa11 Apertures}

For an aperture in a vertical wall, a simple theory leads to a prediction for the critical inflow at the aperture which just prevents hot gases from escaping the fire space. The theory is most appropriate for the case where the aperture extends from the floor to the ceiling, Fig. 1. Cold air from the surrounding space flows through the aperture of widh $W$ into the fire ("hot") space, forming a jet into the fire space which has a vena contracta considerably narrower than the width of the aperture. Since pressures increase more rapidly with depth in the cold space than in the hot space, the critical condition of zero, local velocity in the aperture is first reached at the top of the aperture as the overall throughflow is gradually reduced. Any further reduction in throughflow causes hot gases to back up into the cold space. Bernoulli's equation can be written for any elevation, $y$, between the quiescent cold space and the vena contracta, where the horizontal velocity profile is considered uniform, which provides an expression for $u(y / H)$ in the vena contracta. At the critical condition, $u(1)=0$, which fixes the vertical velocity profile in the vena contracta in terms of the temperature distribution in the hot space. The average (cold) velocity through the aperture at the critical condition, $\bar{u}_{\mathrm{c}}$, can be defined from the total volumetric flow rate and the aperture area, whose nondimensional form,

$\mathrm{Fr}_{\mathrm{c}}=\overline{\mathrm{u}}_{\mathrm{c}} /\left(2 \mathrm{gH} \Theta_{\mathrm{H}}\right)^{1 / 2}$,

is the critical Froude number.

The following prediction is established for the critical Eroude number, following the procedure outlined above: 

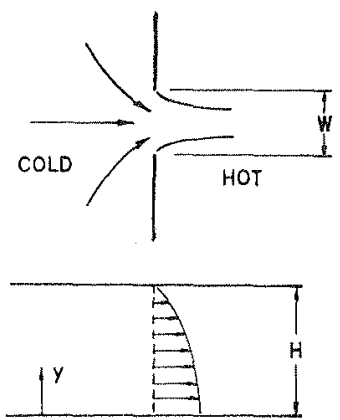

Figure 1 Critical flow conditions at a wall aperture extending from floor to ceiling.

$\mathrm{Fr}_{\mathrm{c}}=\mathrm{CP}$.

Here, $\mathrm{C}$ is the discharge coefficient or coefficient of contraction, often found to be near 0.6 for isothermal flows through sharp-edged circular and slot orifices. The quantity, $P$, is a temperature distribution parameter for the hot space, defined:

$P=\int_{0}^{1}\left[\int_{y / H}^{1}\left(\theta / \theta_{H}\right) d\left(y^{\prime} / H\right)\right]^{1 / 2} d(y / H)$.

For a uniform vertical temperature profile, $P=2 / 3$.

If the aperture does not extend from floor to ceiling, there are difficulties with the simple theory since it cannot be assumed that there is no contraction of the cold jet into the hot space in the vertical direction. One might still expect $\mathrm{Eq}$. (5) to be applicable, with $\mathrm{H}$ (in definition of $\mathrm{Fr}_{\mathrm{f}}$ and $\mathrm{P}$ ) taken as the height of the aperture, but possibly with a different value for the coefficient, $C$.

Viscous effects in the aperture flow, if they exist, are expected to depend on the Grashof number (square of the ratio of the Reynolds number, $\rho_{\mathrm{c}} \overline{\mathrm{u}}_{\mathrm{c}} \mathrm{H} / \mu$, to the Froude number):

$\mathrm{Gr}=\mathrm{g} \rho_{\mathrm{c}}{ }^{2} \Theta_{\mathrm{H}}\left(H \mathrm{~W}^{2}\right) / \mu^{2}$,

where $\mu$ is evaluated at the mean of the hot and cold temperatures. The relative geometry of the aperture, such as $\mathrm{H} / \mathrm{W}$ for rectangular apertures, may also be important.

\section{Ceiling Apertures}

Transitions between bidirectional and unidirectional flows, of the kind included in the studies of Epstein et al. [2,3] and the issue of concern in connection with ceiling apertures, are extremely complex and no theory is attempted for this case.

In general, the state of the flow at a horizontal aperture, with a hot fire space below and cold ambient space above, will be governed by Froude and Grashof numbers akin to those defined for vertical openings in Eqs. (4) and (7), except $\mathrm{H}$ is replaced by the aperture width, W. The critical Froude number for ambient air flowing into the fire space, just sufficient to pre- 
vent escape of smoke, will be a function of the Grashof number, where the two nondimensional groups are defined:

Critical Froude Number: $\mathrm{Er}_{\mathrm{c}}=\overline{\mathrm{u}}_{\mathrm{c}} /\left(2 \mathrm{gW} \mathrm{C}_{\mathrm{cl}}\right)^{1 / 2}$

Grashof Number: $G r=g \rho_{c}^{2} \theta e \mathrm{w}^{3} / \mu^{2}$.

Here, $\theta_{0}$ is $\Delta \mathrm{T} / \mathrm{T}$ evaluated at the ceiling level (away from the thermal boundaryllayer).

The critical Froude number may be expected to depend on the aperture geometry. However, it is reasonable to expect that this dependence will not be very large if $W$ is taken as the smaller dimension of rectangular apertures. Little can be said about other aperture geometries, a priori.

It is also possible that the critical Froude number may not be completely independent of the vertical. temperature profile in the hot space. However, such effects should not be significant when vertical temperature variations over depths on the order of $W$ below the ceiling are small compared to $\Delta \mathrm{T}_{\mathrm{Cl}}$.

\section{EXPERIMENTAL ARRANGEMENT}

\section{Wa.11 Apertures}

Most of the experiments were conducted in a reduced scale facility having a ceiling height of $0.61 \mathrm{~m}$. The facility consisted of a square fire compartment measuring $2.44 \mathrm{~m}$ on the side, with an air supply plenum attached to one side of the compartment, in which various wall apertures were mounted, and with two floor-to-celing ventilation openings for the fire in the opposite side. Figure 2 illustrates the wall apertures investigated, formed by $2.7 \mathrm{~mm}$ or $1.7 \mathrm{~mm}$ thick steel plating.

As fire source was used a $0.31 \mathrm{~m}$ diameter "sandbox" gas burner flush with the floor near the ventilation wall, burning propylene or propane at rates from 8 to $165 \mathrm{~kW}$ (corresponding to $270-5600 \mathrm{~kW}$ in a $2.5 \mathrm{~m}$ high room according to scaling rules [7]). Temperatures were measured at five elevations from floor to celling in the fire compartment and in the air plenum, and the pressure differential between the plenum and fire compartment was monitored at mid-height of the facility. An extinction photometer was mounted in the air supply plenum to monitor any penetration of smoke from the fire compartment.

Following ignition, temperatures in the fire compartment were allowed to approach a steady state. Then the flow rate of air from the plenum was decreased in 10 percent steps until the first indication of smoke by the photometer in the plenum. The critical flow rate was taken as the average of the first flow rate indicating presence of smoke and the immediately preceding flow rate.

\section{Ceiling Apertures}

For investigation of ceiling apertures, the air plenum was positioned over apertures in the ceiling of the fire-compartment half opposite the burner. Eigure 3 shows the various ceiling apertures, cut in $1.7 \mathrm{~mm}$ steel plates. 

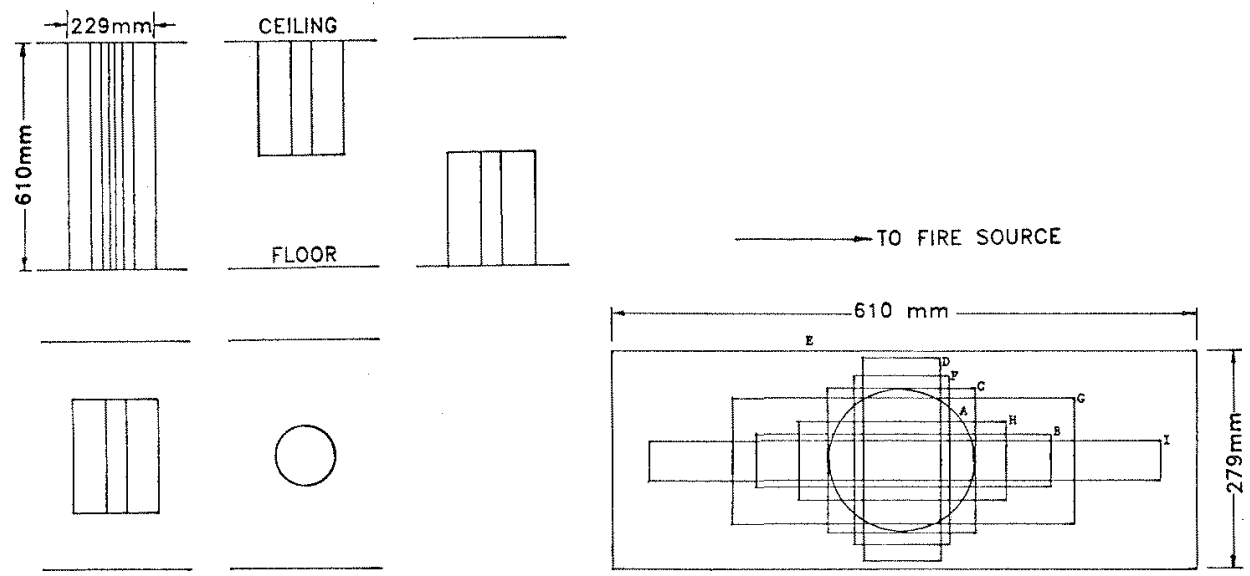

Figure 2 Wall apertures, varying in width from 229 to $16 \mathrm{~mm}$.

Figure 3 Ceiling apertures, varying in width from 279 to $45 \mathrm{~mm}$.

\section{Larger-Scale Facility}

A fire test room was available from a previous program to investigate door-size apertures $(0.92 \mathrm{~m} \times 2.03 \mathrm{~m})$ in wall and ceiling. The fire test room, measuring $3.7 \times 7.3 \times 2.4 \mathrm{~m}$ high, was exhausted by a blower via $0.61-\mathrm{m}$ diameter ducting attached to one of the walls of the test room and provided with flow metering. Vertical thermocouple traverses were provided in the room. As a fire source, heptane was floated on water in a $0.5 \mathrm{~m}$ diameter container (approximate heat-release rate of $150 \mathrm{~kW}$ ). The critical flow conditions for escape of smoke were determined by visual observation of the aperture flows, which were illuminated by flood 1 ight. Observations began after temperatures in the room had stabilized.

In analogy with the reduced-scale tests, the exhaust flow was reduced in small steps until smoke puffs were first observed to escape into the laboratory (at the top of the door, or above central regions of the ceiling aperture). It was possible to determine rather narrow flow brackets, no smoke versus smoke into the laboratory, for both apertures.

\section{CRITICAL FROUDE NUMBERS}

\section{Wall Apertures}

Figure 4 presents critical Froude numbers for the wall apertures, defined in Eq. (4), as a function of the temperature distribution parameter, $\mathrm{P}$, defined in Eq. (6). (Some tests, not represented in the figure, had to be discarded because unacceptable density variations built up in the air plenum, due to heat transfer from the fire compartment to the plenum through the common wall.) The temperature data for Fig. 4 were averaged from two vertical traverses positioned two ceiling heights apart, symmetrically located left and right of the aperture, one ceiling height in front of the aperture wall.

The straight, dashed line is a fair representation of the data, drawn to satisfy $\mathrm{Eq}$. (5). This line corresponds to a discharge coefficient, $\mathrm{C}=0.64$. 


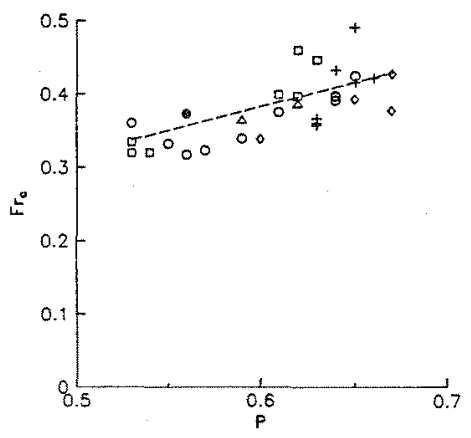

Figure 4 Critical Froude number for wall apertures: O floor-to-ceiling apertures; + high apertures; $\Delta$ low apertures, $\square$ central apertures; $\diamond$ central circular aperture; doorway, larger-scale.

Note that most of the data are well represented by this line, i.e., the floor-to-ceiling apertures, high rectangular apertures, low rectangular apertures, central rectangular apertures, central circular aperture, and the normal-size doorway. Admittedly, the scatter may hide secondary effects of aperture shape and elevation.

The range in $P$ from 0.53 to 0.67 may cover most practical cases, from highly non-uniform vertical temperature profiles at low heat release rates to nearly uniform profiles at high heat release rates. The accompanying variation in $\mathrm{Fr}_{\mathrm{c}}$ is seen to be 0.32 to 0.43 . No effect of the Grashof number (Eq. (7)) has been seen in the data of Fig. 4.

\section{Ceiling Aperture}

Critical Froude numbers for ceiling apertures, defined in Eq. (8), are presented in Fig. 5 as a function of the Grashof number, defined in Eq. (9). The temperature data for Fig. 5 were averaged from the topmost thermocouples (at a depth of $0.04 \mathrm{H}$ below the ceiling) of two vertical traverses. Referring to Fig. 3, the two traverses were located on the long axis of aperture $D$, one ceiling height to either side of the center of the aperture.

In this case, there is a definite effect of the Grashof number, with a high-Grashof number asymptote near $\mathrm{Fr}_{\mathrm{c}}=0.23$ and an apparent low Grashof number asymptote near $\mathrm{Fr}_{\mathrm{c}}=0.38$, separated by a transition range. While one would expect a leveling of of critical Froude numbers with increasing Grashof number, associated with transition to turbulent flow, a leveling off of critical froude numbers at low Grashof numbers was unexpected. However, in all likelihood, there is a slow rise of critical Eroude numbers for Grashof numbers decreasing below $10^{\circ}$, but the data are not sufficient to establish the actual behavior.

There is no apparent effect of aspect ratio in Fig. 5. Nor is there an effect of the orientation of a rectangular aperture. This latter finding, together with the small effect observed of a partial partition for Aperture I (floor-to-ceiling partition between the fire source and the aperture, extending to within $0.31 \mathrm{~m}$ of opposing walls of the fire compartment), imply that gas motion in the ceiling gas layer had little effect on the critical conditions for escape of smoke. 


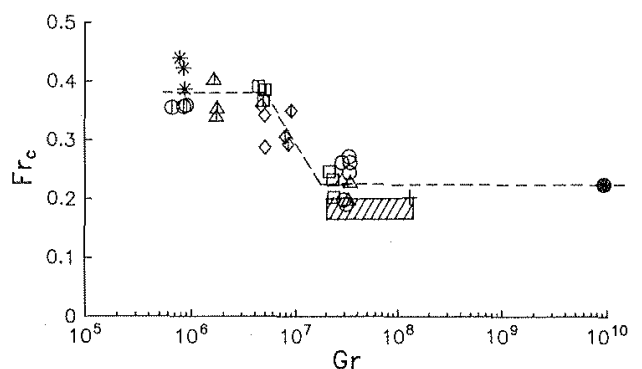

Figure 5 critical Froude number for ceiling apertures. Except for

(normal doorway), the symbols represent apertures identified with corresponding letters in Fig. 3 according to: $O(A), \triangle(B), \triangle(C), D(D),+(E)$,

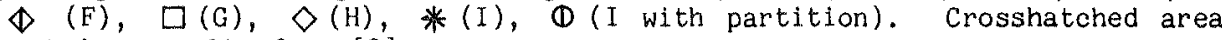
contains results from [3].

\section{PRESSURE DIFEERENTIALS AND DISCHARGE COEFFICIENTS}

Pressure differentials measured across the floor-to-ceiling wall aperture at the critical Froude numbers, adjusted to the top of the aperture by hydrostatic corrections using the vertical temperature profiles, were verified to be close to zero, as assumed in the theory. The discharge coefficient best fitting the theory for critical conditions to the experiments, $C$ $=0.64$, is close to the value 0.61 often found to represent isothermal forced flows through sharp-edged orifices and slots. Consequently, it appears safe to assume a discharge coefficient of comparable magnitude for calculation of all supercritical flows through wall apertures.

For the celling apertures, the measured pressure differentials were converted, using hydro-static corrections, to pressure differentials across the ceiling, at the level of the ceiling. Most of the data pertained to the critical Froude numbers and slightly larger, but limited data were also obtained at considerably larger Froude numbers. Discharge coefficients, $C$, were calculated from:

$\dot{\mathrm{m}}=\mathrm{CA}(2 \mathrm{p} \mathrm{c} \Delta)^{1 / 2}$,

where $\dot{m}$ is the mass flow rate through the aperture for a given pressure differential across the ceiling, $\Delta p$. The discharge coefficients are plotted as a function of Eroude number in Fig. 6. For the high asymptotic range $\left(\mathrm{Gr} \geq 2 \cdot 10^{7}\right)$, the familiar isothermal. flow limit, 0.61 , appears to be approached at a Froude number of 1.5 .

The pressure differential across the ceiling can be calculated from (based on eq. (10)):

$\Delta p=(\mathrm{Fr} / \mathrm{C})^{2} \mathrm{p}_{\mathrm{c}} \mathrm{gW \theta _{ \textrm {cl } }}$.

It may be verified from Fig. 6 that the ratio $(\mathrm{Fr} / \mathrm{C})^{2}$ varies relatively slowly with $\mathrm{Fr}$ in the Fr range $0.23-0.6$, implying that the pressure difference across the ceiling in this regime does not vary significantly with the flow rate. 


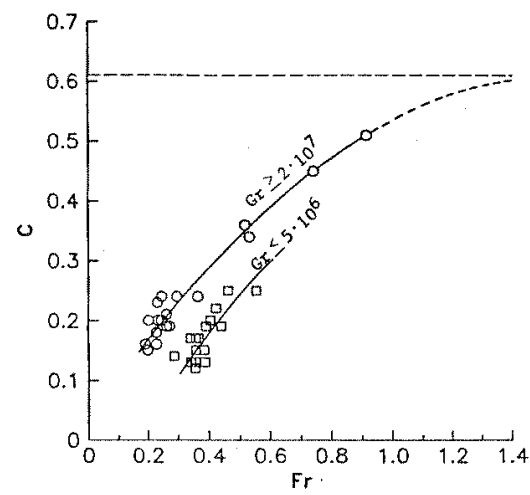

Figure 6 Discharge coefficients for ceiling apertures.

\section{COMPARISON WITH PREVIOUS WORK}

The critical Froude number derived from Thomas' work to prevent smoke from backing up in a horizontal passage [1], Eq. (1), can be converted to the form adopted in the present study, with the result:

$\mathrm{Fr}_{\mathrm{c}}=0.79\left[\left(\Delta \mathrm{T}_{\text {ave }} / \mathrm{T}_{\text {ave }}\right) /\left(\Delta \mathrm{T}_{\mathrm{H}} / \mathrm{T}_{\mathrm{H}}\right)\right]^{1 / 2}$

The vertical temperature distributions in Thomas' experiments are not known. It will be assumed that they were rather steep, with a representative value of 0.5 for the temperature ratio within brackets in $\mathrm{Eq} .(12)$, as for the lowest heat release rate experiments in the current study. Then Thomas' result corresponds to $\mathrm{Fr}_{\mathrm{c}}=0.56$. For a flow passage, having a discharge coefficient of 1, the present results correspond to (cf. Eq. (5)):

$\mathrm{Fr}_{\mathrm{c}}=\mathrm{P}$

The experiments indicated a close correlation between $\mathrm{P}$ and the temperature ratio in $\mathrm{Eq}$. (12); for a temperature ratio of 0.5 , the value $P=0.55$ was indicated. Hence the present experiments imply the value $\mathrm{Fr}_{\mathrm{c}}=0.55$ for a horizontal passage, in good agreement with the value deduced from Thomas' experiments, $\mathrm{Fr}_{\mathrm{c}}=0.56$.

The critical Froude numbers, quoted in the Introduction, associated with the measurements of Epstein and Kenton [3] using brine/fresh water and circular openings, are contained within the crosshatched region in Fig. 5. It is recalled that these measurements pertain to the $L / D$ range $0.01-0.06$ and the Grashof number range indicated in the figure. There is surprisingly good agreement, considering the difference in experimental methods. It may be emphasized that $\mathrm{L} / \mathrm{W}$ ratios in the present experiments did not exceed 0.04 .

\section{CONCLUSIONS}

1. Critical Froude numbers of air inflow to prevent escape of smoke from wall apertures, $\mathrm{Fr}_{\mathrm{C}}$ (Eq. (4)), were found to be insensitive to the aperture geometry, consistent with simple theory and an experimental discharge coefficient of 0.64 . Values of $\mathrm{Fr}_{\mathrm{c}}$ varied from 0.32 to 0.43 in the tested range of vertical room temperature distributions (Fig. 4). 
2. Critical Froude numbers of air inflow to prevent escape of smoke from ceiling apertures, $\mathrm{Fr}_{\mathrm{c}}$ (Eq. (8)), were also insensitive to aperture geometry and approached an asymptotic value $\mathrm{Fr}_{\mathrm{c}}=0.23$ at Grashof numbers (Eq. (9)) greater than $2 \cdot 10^{7}$. An apparent asymptote was also reached at Grashof numbers smaller than $5 \cdot 10^{6}, \mathrm{Fr}_{\mathrm{c}}=0.38$.

3. Discharge coefficients for ceiling apertures were found to increase with the Eroude number (Fig. 6), starting near 0.19 at $\mathrm{Fr}=\mathrm{Fr}_{\mathrm{c}}=0.23$ and approaching 0.61 , the familiar isothermal value for sharp-edge orifice flows, near $\mathrm{Fr}=1.5$ (high Grashof number range). Discharge coefficients for wall apertures can be assumed to remain near 0.64 (Conclusion 1) as Froude numbers increase above Fr $_{\mathrm{c}}$.

\section{REFERENCES}

1. Thomas, P.H., "The Movement of Snoke in Horizontal Passages Against an Air Flow," Fire Research Note No. 723, Fire Research Station, Boreham Wood, Herts, England, September 1968.

2. Epstein, M., "Buoyancy-Driven Exchange Flow Through Small Openings in Horizontal Partitions," ASME Journal of Heat Transfer, 110, 885-893, 1988 .

3. Epstein, M. and Kenton, M.A., "Combined Natural Convection and Forced Flow Through Small Openings in a Horizontal Partition, with Special Reference to Flows in Multicompartment Enclosures," ASME Journal of Heat Transfer, 111, 980-987, 1989.

4. Shaw, B.H., "Heat and Mass Transfer by Natural Convection and Combined Natural Convection and Forced Air Flow Through Large Rectangular Openings in a Vertical Partition," Symposium on Heat and Mass Transfer by Combined Forced and Natural Convection, The Institution of Mechanical Engineers, 31-39, 1971.

5. Steckler, K.D., Baum, H.R., and Quintiere, J.G., "Fire Induced Flows Through Room Openings - Flow Coefficients," Twentieth Symposium (International) on Combustion, The Combustion Institute, 1591-1600, 1984.

6. Heskestad, G. and Spaulding, R.D., "Inflow of Air Required at Wall and Ceiling Apertures to Prevent Escape of Fire Smoke," FMRC J.I. OQ4E4.RU, Factory Mutual Research Corporation, Norwood, MA, July 1989.

7. Thomas, P.H., "Studies of Fires in Buildings Using Models," Research, $13,87,1960$. 